Earth \& Environment | Jenny Stavrakou \& Maite Bauwens

\title{
What can COVID-19 shutdowns teach us about reducing air pollution?
}

The impact of COVID-19 on manufacturing, travel and production has proved unexpected opportunity for a global experiment for atmospheric scientists. Drs Jenny Stavrakou and Maite Bauwens at the Royal Belgian Institute for Space Aeronomy are experts in atmospheric modelling and interpretation of satellie measurements of air pollution. They have been changes have affected our environment and how we might use this to improve air quality in the future.

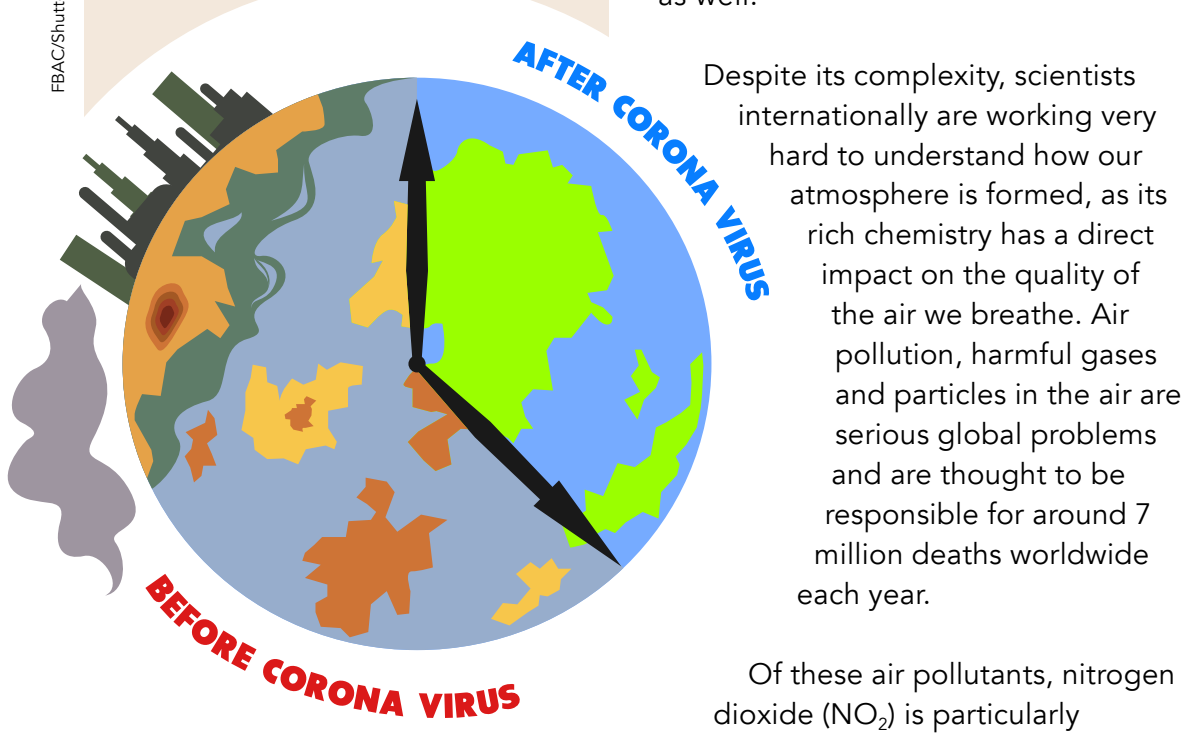
of the atmosphere are home to different types of chemistry as not all wavelengths of light can pass through all the layers. Different regions tend detrimental in terms of impact on

High concentrations of $\mathrm{NO}_{2}$ itself $\mathrm{can}$ irritate the lungs and aggravate other respiratory diseases, like asthma. $\mathrm{NO}_{2}$ can also go on to react and form particulate matter and ozone - both of which have similar, problematic effects. In the environment, $\mathrm{NO}_{2}$ contributes to acid rain, damaging forests, coasts an even causing buildings in our cities

\section{to crumble.}

Dr Jenny Stavrakou and Dr Maite Bauwens at the Royal Belgian Institute for Space Aeronomy have been

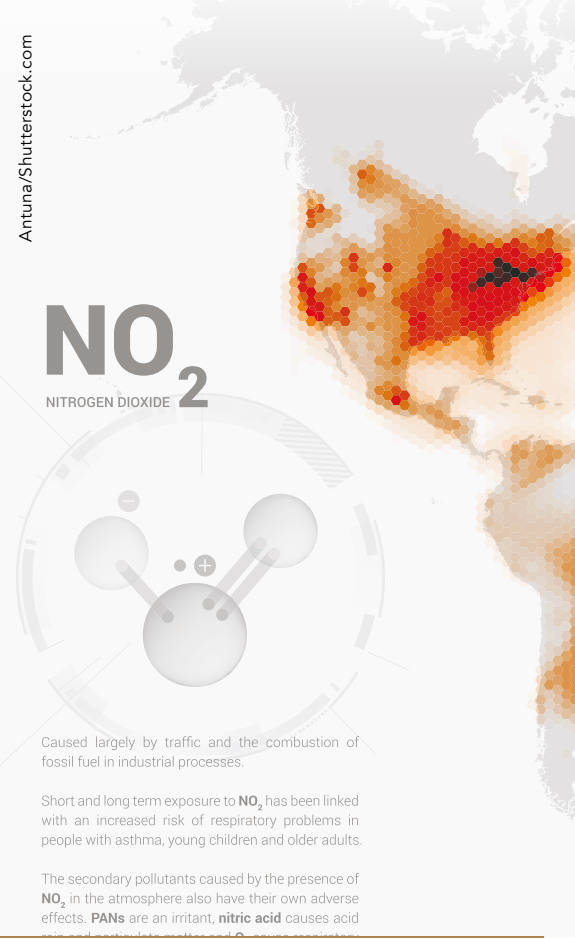

tool, the Tropospheric Monitoring Instrument (TROPOM), aboard the dedicated to the daily monitoring of air pollution worldwide. They have been watching with great interest how $\mathrm{NO}_{2}$ emissions have been strongly reduced in response to the COVIDrelated restrictions of human activity e.g. stay-at-home orders, travel bans and a fall in manufacturing. From the data they are recording, the team is working out exactly what the changing patterns of $\mathrm{NO}_{2}$ emissions mean for our environment and atmosphere, and what we can learn to help reduce air

$\mathrm{NO}_{2}$ SOURCES

Generally $\mathrm{NO}_{2}$ and related

molecules (known as $\mathrm{NO}^{2}$ a formed predominantly from the combustion commil fuels. Motor vehicles are a . cookers, produce $\mathrm{NO}_{2}$. While

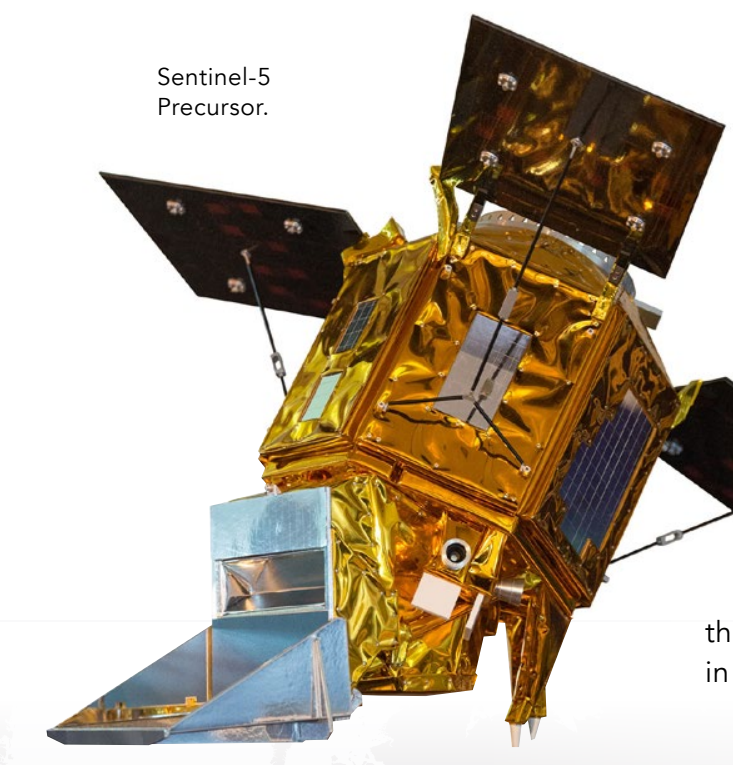

$\mathrm{NO}_{2}$ itself can irritate the lungs and aggravate other respiratory diseases.

very low concentrations are harmless, it can start to have exceed 0.1 pm.
entions The constant
circulation and
mixing of the
atmosphere mean
that even if the pollution is reaeated
in a localised area, it will eventually
circulate globally. With
TROPOM and Bauwens have

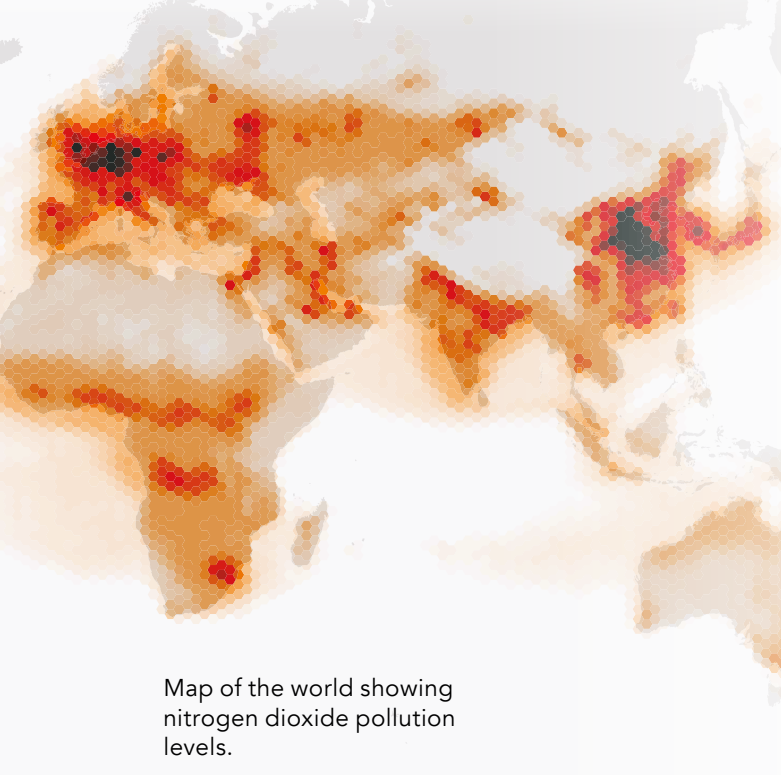
been focusing on the $\mathrm{NO}_{2}$ levels in cities. Whil they have found some reduction in $\mathrm{NO}_{2}$ levels from new environmenta legislation aimed at minimising air pollution the most significant change from the COVID-19 pandemic.

What the researchers learned was that, in many of the epicentres of the pandemic, the reduction
in human activity caused a sharp and dramatic
Drs Stavrakou and Bauwens could therefore take a temporary glimpse of

WINDOW OF OPPORTUNITY

$\mathrm{NO}_{2}$ levels largely rebounded as economic activities have restarted, global econ China and India. Will somewhat reduced post-pandemic this has given Drs Stavrakou and Bauwens unique data to use to try and understand exactly what and how different factors contributed to the observed reduction in $\mathrm{NO}_{2}$ levels. played a role, meteorological factors played a role, meteorologica
also influence $\mathrm{NO}_{2}$ levels.

By having such extensive daily measurements on $\mathrm{NO}_{2}$ levels, the data from TROPOMI can be used to refine atmospheric models and gives us a chance to see whether such models $\mathrm{NO}_{2}$ sources globally.

TROPOMI, which was launched on the Sentinel-5 satellite back in 2017, is not the only instrument to measure our atmosphere. Drs Stavrakou and Bauwens have also been comparing this with data from the Ozone Monitoring Instrument (OMI), another satellite launched in 2004, and found an excellent consisten
two satellite datasets. sudden reduction in the number of 

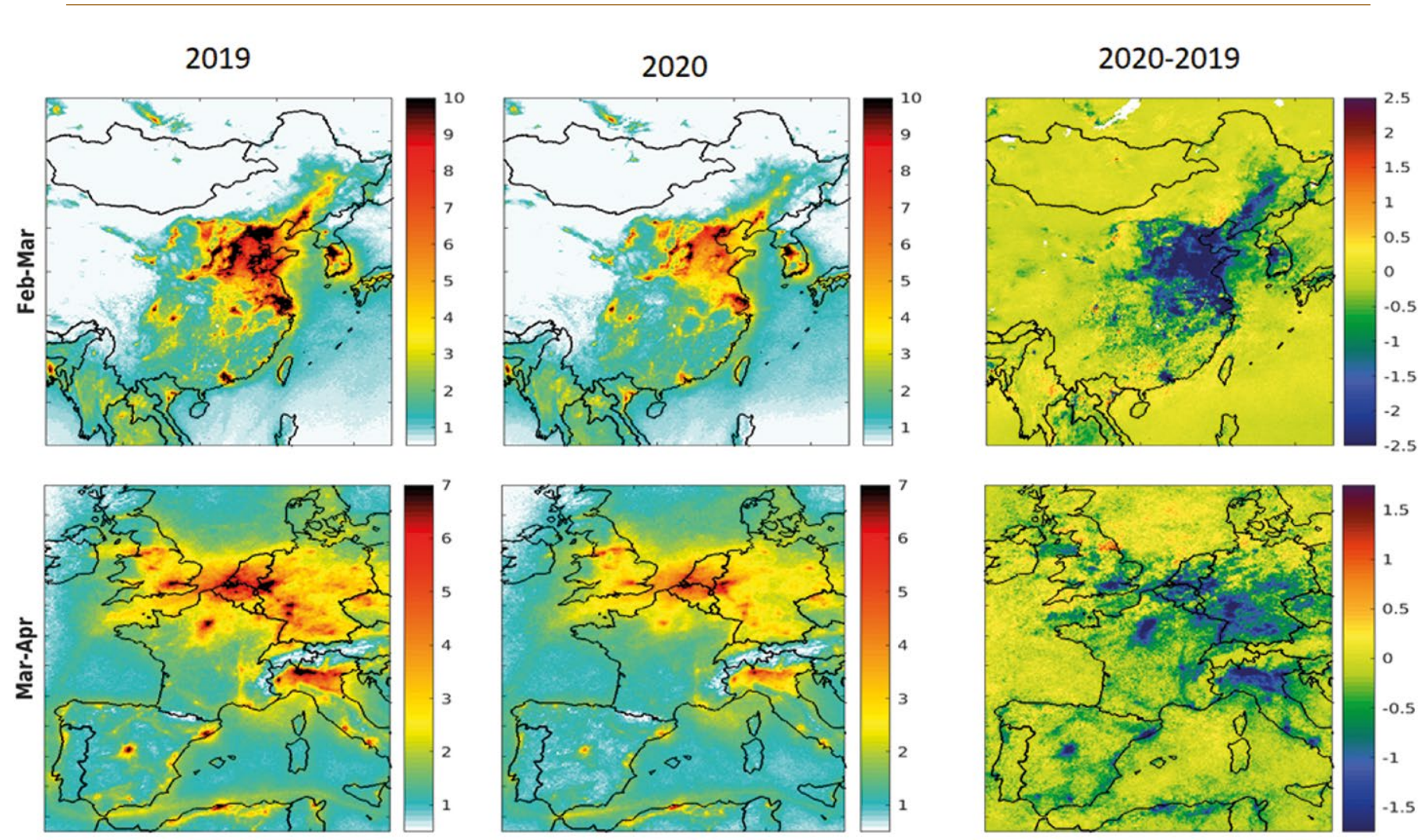

Average TROPOMI NO $\mathrm{N}_{2}$ column in 2019

\section{PROBLEM GASES}

One of the reasons $\mathrm{NO}_{2}$ and the whole family of nitrogen oxides are so problematic for health and the environment are their effects on $\mathrm{NO}_{2}$. There is some concern that $\mathrm{N}_{2}$ and ozone can work together to respirator systrive effects on the respiratory system. In the stratosphere, nitrogen oxides can destroy ozone, leading to a thinning of the global ozone layer which protects us from
dangerous solar ultraviolet light.

$$
\begin{aligned}
& \text { an unprecedented drop in emissions } \\
& \text { in many regions around the world } \\
& \text { and cast light on the response of the } \\
& \text { atmospheric system to the emission } \\
& \text { disruption caused by the pandemic. } \\
& \text { Generally, regions with reduced NO, } \\
& \text { production also showed decreased } \\
& \text { ozone production, but this was not } \\
& \text { the case everywhere. Surprisingly, } \\
& \text { in heavily polluted regions during } \\
& \text { winter, surface ozone has showed } \\
& \text { increases in response to the drop of } \\
& \mathrm{NO}_{2} \text { pollution. This is because the }
\end{aligned}
$$

wide and large the knock-on effects from $\mathrm{NO}_{x}$ could be.

\section{AIR QUALITY CONTROL}

\section{occurred in the world}

during different time periods with

different degrees of severity (which

could be mapped in how much the

$\mathrm{NO}_{2}$ emissions were reduced) a wealth of data was generated showing how rmaller or bigger $\mathrm{NO}_{2}$ concentration eductions would mpact the overall

mical composition and how all of this could by the weather conditions. and Bauwens's make full use of the high-resolution capabilities of The reduction of $\mathrm{NO}_{x}$ concentrations during the pandemic also led to a cascading change in the concentrations

As TROPOMI keeps of many other chemical species. on measuring
$\mathrm{NO}_{x}$ emission levels, COVID-19 allow them to

identify exactly which regions and areas the $\mathrm{NO}_{2}$ emission originates from. Their measurements showed a reduction of up to $50 \%$ in $\mathrm{NO}_{x}$ emission in some of China's cities while COVID-19 lockdowns were in place. They have also been able to compare their satellite observations to were able to simulate for the first tine

relationship between $\mathrm{NO}_{2}$ and ozone concentrations and overall air quality is highly nonlinear. This shows that reduction of $\mathrm{NO}_{2}$ emissions is often not enough to solve the pollution problem as a whole. The reduction of $\mathrm{NO}_{x}$ concentrations during the pandenic also led to a cascading change in the concentrations of many
other chemical species, showing how lockdowns have provided a unique

chance to examine how human activity atmosper the composition of our periods of $w$ h many cities enjoying perods of sign ficantly reduced pollution the question respiratory intation. Now new knowledge to inform public policy going forward to address another public health crisis - air pollution.

\section{Behind the Research}

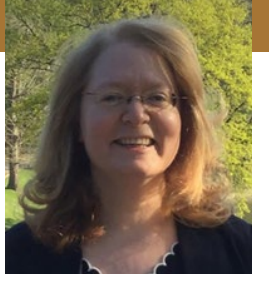

Dr Jenny

Stavrakou

E: ienny@aeronomie.be

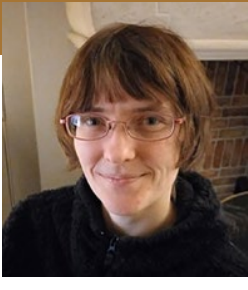

Dr Maite

Bauwens

E: maite.bauwens@aeronomie.be

W: http://tropo.aeronomie.be

Research Objectives

Drs Stavrakou and Bauwens observed the change in $\mathrm{NO}_{2}$ levels in major cities duning and analysed the evolution of other major pollutants. Their objective is to interpret these observations using from space using sophisticated inversion techniques.

\section{Detail}

Royal Belgian Institute for Space Aeronomy (BIRA-IASB) Avenue Circulaire 3,1180 Brussels, Belgium

Bio

Dr Jenny Stavrakou graduated with a PhD in Physics a the University of Aix-Marseille (France) and joined the research group of Tropospheric Chemistry Modelling at BIRA-IASB in 2001, where she now occupies a Senior Scientist positio

Dr Maite Bauwens is postdoctoral researcher at the group of Tropospheric Chemistry Modelling of BIRAussels (VUB), Belgium.

Funding

- Belgian Science Policy Office (BELSPO) through the PRODEX TROVA project (2016-present) - European Space Agency (ESA) through the ICOVAC project

\section{Collaborators}

-Jean-François Müller, Head of the Tropospheric Chemistry Department, for his valuable advice Karolien Lefever, Head of the Communication Department, for her help, discussions and support throughout this study

- All staff of the communication cell who have contributed and are still contributing to this project ESA Sentinel-5P Mission team for making TROPOMI satellite data publicly available

KNMl inste product development team from the An

\section{References}

Bauwens, M., Compernolle, S., Stavrakou, T., Müller, J.-F. et al. (2020). Impact of Coronavirus Outbreak on $\mathrm{NO}_{2}$ Pollution Assessed Using TROPOMl and OMI Observations. Avaible at: hesp//doiorg/10,1029/2020G1087978

Shi, X. and Brasseur, G.P. (2020). The response in air quality to the reduction of Chinese Economic Activities during the COVID-19 Outbreak. Geophysical Research Letters, 47(11), e2020GL088070. Available at:

https://doi.org/10.1029/2020GL088070

Gaubert, B., Bouarar, I., Doumbia, T., Liu, Y. et al. (2020). Global Changes in Secondary Atmospheric Pollutants during the 2020 COVID-19 Pandemic. Journal of Geophysical Research: Atmosphere. Available at: https://doi.org/10.1002/essoar.10504703.1 [Preprint]

\section{Personal Response}

Do you think the COVID-19 pandemic has raised awareness of air pollution and the importance of minimising $\mathrm{NO}_{2}$ emissions?

II The air pollution changes due to the lockdowns attracted a great deal of media attention and mobilised in an unprecedented way the community of atmospheric scientists to work together and analyse the observed air polution patterns. Besides is tragic dimension, hie crucial and must be urgently tackled. As clean air swiftly returned in many polluted cities, from New York to Delh and Beijing, the pandemic offered a glimpse of what

of sustainable policies to make our cities healthier.

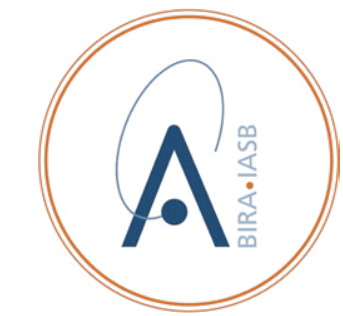

